\title{
Structural and Textural Evolution during Cold Work in Ti-Rich Ni-Ti Shape Memory Alloy
}

\author{
A. S. Paula and F. M. Braz Fernandes ${ }^{\mathrm{a}, 1}$ \\ CSN - GGDP/GPD, Rod. BR 393, km 5001 - Lúcio Meira, s/n - Vila Santa Cecília - Volta Redonda - RJ - \\ Brazil - CEP 27260-390 \\ UNIFoa - Centro Universitário de Volta Redonda, Campus Três Poços - Av. Paulo Erlei Alves Abrantes, 1325 , \\ Três Poços - Volta Redonda - RJ - Brazil - CEP 27240-560 \\ ${ }^{1}$ CENIMAT - I3N, Campus da FCT/UNL, 2829-516 Monte de Caparica, Portugal
}

\begin{abstract}
The properties and cost have made the Nickel-Titanium (NiTi) shape memory alloys (SMA) attractive for a variety of applications wherein shape memory effect (SME) / superelasticity (SE) and biocompatibility are important. Anisotropy of the shape recovery associated with shape memory effect strongly depends on the type of preferential orientation, that is present, as well as the 'strength' of the texture. The goal of the present work is to investigate the structural and textural evolution in annealed (at $500^{\circ} \mathrm{C}$ for 30 minutes in air) Ti-Rich Ni-Ti SMA (Ni$51 \mathrm{at} \% \mathrm{Ti})$ when subjected to cold rolling at 8 distinct thickness reduction $(2,4,6,8,10,20,30$ and 40\%). The textural results were obtained by X-Ray Diffraction (XRD) at room temperature (B19' phase). The structural evolution was observed by temperature dependent XRD spectra. Indentation hardness test at room temperature (B19') was also performed. Differential Scanning Calorimetry (DSC) was used to identify the transformation temperatures and the phase stabilization after all steps of cold work treatments.
\end{abstract}

\section{Introduction}

Ni-Ti is a shape memory alloy with composition close to equiatomic, and is capable of two successive athermal martensitic phase transformations while cooling from its higher temperature austenite (B2 - $\mathrm{CsCl}$ crystal structure) phase. In Ti rich Ni Ti SMA, the first phase transformation during cooling is observed above room temperature and results in the R-phase (trigonal crystal structure with rhombohedral distortion in angle $\alpha$ ); the second one, occurs around room temperature and results in M-phase (B19' - monoclinic structure), often with a fine lath morphology. These transformations give rise to thermoelasticity and twin deformations in $\mathrm{Ni} \mathrm{Ti}$ alloy facilitating shape memory effect (SME) [1].

Ni-Ti SMA is highly ductile, compared with other intermetallic compounds, and, when subjected to tensile loading, elongations above $20 \%$ are commonly reported [2-4]. Yet, in the martensitic condition, these alloys possess a low symmetry B19' monoclinic crystal structure, which might restrict dislocation movement to some extent. In contrast, significant dislocation activity has been reported in the alloys deformed in tensile/compression mode, where dislocation generation and their pile-ups at the twin boundaries have been observed [4,5].

Several studies are dedicated to the influence of the texture on thermomechanical response of the SMAs [6-15]. Thermal cycling, rolling or drawing are found to develop specific texture in metals and alloys. They result in different anisotropy characteristics (mechanical, electrical and magnetic behavior). NiTi SMAs are also sensitive to these effects. The texture is found to give rise to anisotropy in transformation recovery strain [10]. The cold work in Ni-Ti SMA [5] is produced in the martensitic state and plastic deformation does not occur in the first austenite grains, but in the martensite variants with different crystallographic orientations. The plastic deformation includes primarily the martensite reorientation of martensite variants, and, only after that, the dislocation generation inside each martensite variant.

In the present work we investigated how distinct levels of cold work in Ni-Ti SMA can promote structural and crystallographic texture modifications.

\footnotetext{
a e-mail: fbfefct.unl.pt
}

This is an Open Access article distributed under the terms of the Creative Commons Attribution-Noncommercial License (http://creativecommons.org/licenses/by-nc/3.0/), which permits unrestricted use, distribution, and reproduction in any noncommercial medium, provided the original work is properly cited. 


\section{Materials and Methods}

The samples for the present study were extracted from straight annealed (as-received condition - AR) Ti rich Ni Ti alloy (Ni-51.0at\%Ti) plate of thickness $2 \mathrm{~mm}$ supplied by Memory-Metalle GmbH, Germany. The samples were analyzed in the following conditions: (i) heat treated at $500^{\circ} \mathrm{C}(\mathrm{HT})$ and (ii) heat treated at $500^{\circ} \mathrm{C}$ followed by cold rolling (TMT) at 8 distinct thickness reduction $(2,4,6,8,10,20,30$ and $40 \%)$. The heat treatment (HT) was performed by holding the specimen at $500^{\circ} \mathrm{C}$ for 30 minutes and subsequently quenching in water at room temperature $\left(\mathrm{T}_{\text {room }}\right)$. The samples were subjected to chemical etching $\left(10 \%\right.$ vol $\mathrm{HF}+45 \%$ vol $\mathrm{HNO}_{3}+45 \%$ vol $\mathrm{H}_{2} \mathrm{O}$ ) in order to remove the oxide layer as well as the layer deformed during the cutting operation.

Samples with a mass ranging from 40 to $50 \mathrm{mg}$ were cut from all specimens for DSC analysis (SETARAM DSC92). The following thermal cycle was used for the DSC tests: start temperature at $\mathrm{T}_{\text {room, }}$ heating to $180^{\circ} \mathrm{C}$, holding for $360 \mathrm{~s}$ and subsequent cooling down to $-30^{\circ} \mathrm{C}$, with heating and cooling rates of $7.5^{\circ} \mathrm{C} / \mathrm{min}$.

The micro hardness tests were performed using a microhardness tester Leitz DURIMET. For each sample ten measurements were performed at $\mathrm{T}_{\text {room }}$ with the load of $200 \mathrm{~g}$.

$\mathrm{XRD}$ analysis was performed using a Bruker diffractometer (rotating anode $-\mathrm{XM} 18 \mathrm{H}, \mathrm{CuK} \alpha$ radiation, $30 \mathrm{kV} / 100 \mathrm{~mA}, \mathrm{D} 5000$ goniometer) with conventional $\theta / 2 \theta$ scanning at $\mathrm{T}_{\text {room, }}$, and texture analysis at $\mathrm{T}_{\text {room }}\left(\mathrm{B} 19^{\prime}\right.$ phase) and $180^{\circ} \mathrm{C}\left(\mathrm{B} 2\right.$ phase - only for HT sample). The rolling direction (RD) was kept aligned in $\varphi=0^{\circ}$, with the transversal direction (TD) in $\varphi=90^{\circ}$.

\section{Results and Discussion}

The Fig.1 show the DSC curves for HT, TMT02, TMT04, TMT06, TMT08, TMT10, TMT20, TMT30 and TMT40 samples.
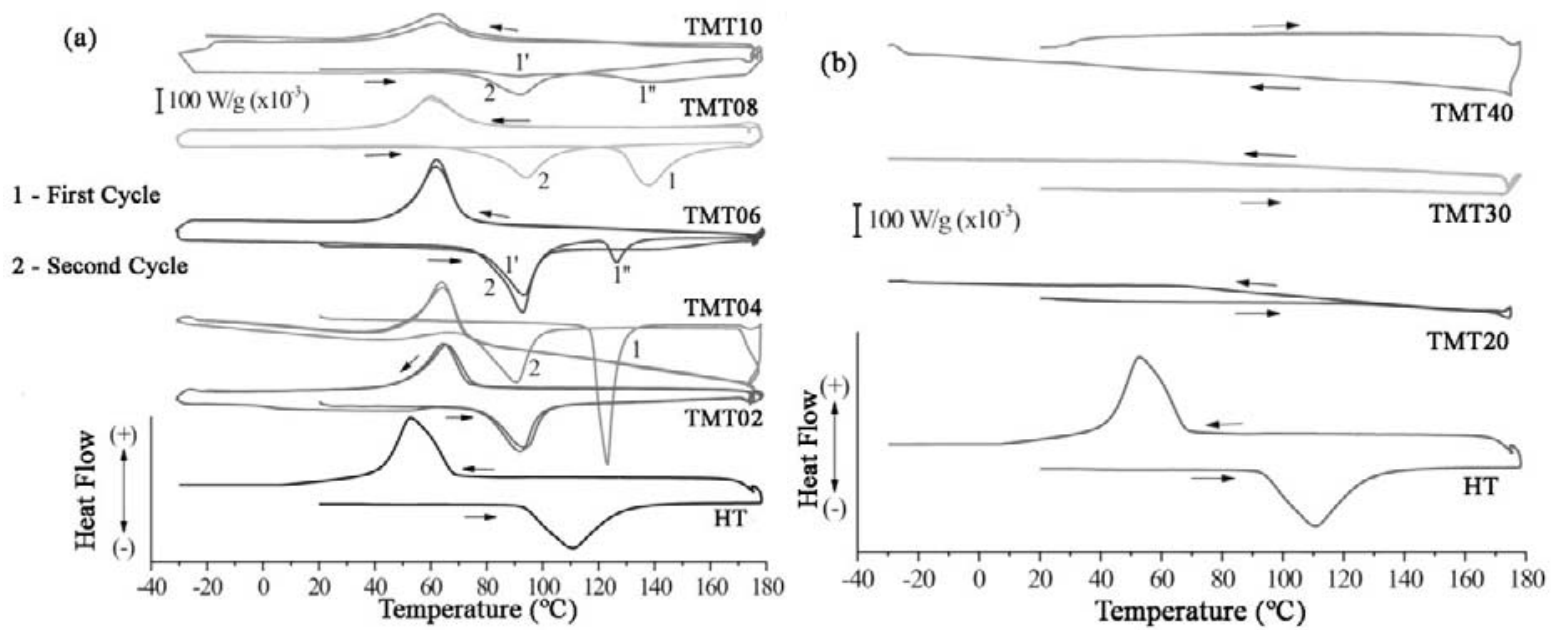

Fig. 1. DSC Curves for heat treated sample (HT) and thermomechanical treated samples (TMT02, TMT04, TMT06, TMT08, TMT10, TMT20, TMT30 and TMT 40 samples).

According to DSC curves and previous works [16-18], for the HT sample, during heating and cooling, one-step (B19’ $\leftrightarrow$ B2) phase transformation is found to be present.

The HT samples were cold rolled (marforming - TMT) with thickness reductions up to $10 \%$ and submitted to two consecutive thermal cycles in DSC with maximum temperature at $180^{\circ} \mathrm{C}$. These samples exhibited a total or partial recovery of shape memory effect (SME) in the second cycle, as shown in Fig. 1a, as a function of the thickness reduction: (i) up to 6\% thickness reduction (TMT02, TMT04 and TMT06, for 2, 4 and $6 \%$ thickness reduction, respectively), occurs a small reduction in the endothermic and exothermic peaks areas compared with the free deformation sample (HT sample), accompanied by a decrease of the reverse transformation temperature and a increase of the direct transformation start temperature; and (ii) above to $6 \%$ thickness reduction occurs a significant reduction of endothermic and exothermic peaks areas compared with the free deformation sample (HT sample), accompanied by a decrease of the reverse transformation temperatures and an increase of the direct transformation temperatures.

This reduction in the DSC peaks area is attributed to partial loss of SME: the deformed martensite (reoriented and with dislocations) is not able to transform to austenite unless it is heated above the recrystallization temperature [16]. The reverse and direct transformation temperatures modifications are attributed to introduction of internal stress fields (associated to dislocation density in the Ni-Ti matrix) in the 
structure, which increase the energy of B2↔B19' transformation, stabilizing the martensite (B19') and promoting the intermediate transformation in R-phase on cooling and on heating.

When the HT samples were cold rolled (marforming - TMT) with high percentage of thickness reduction (above 10\%) and submitted to a thermal cycle in DSC (maximum temperature at $180^{\circ} \mathrm{C}$ ), there was no phase transformation (Fig. 1b - TMT20, TMT30 and TMT40 for 20, 30 and 40\% thickness reduction, respectively). The high degree of plastic deformation increases the dislocation density and suppresses the SME.

When martensite is deformed, their variants are reoriented (with or without domino detwinning and/or assisted detwinning) and, increasing the deformation degree, increases the dislocation density in the microstructure. This effect causes an increase of the yield stress of the material and, as a consequence, a higher hardness.

The Fig. 2 shows the hardness tests results for the HT, TMT02, TMT04, TMT06, TMT08, TMT10, TMT20, TMT30 and TMT40 samples. The average Vickers hardness (HV) is not affected by cold rolling thickness reduction up to $6 \%$. For 8 and $10 \%$, the average HV increases slightly. For $20 \%$ thickness reduction (TMT20 sample) occurs a significant increase in the average HV, until reaching the maximum value for $40 \%$ thickness reduction (TMT40 sample).

The sample with $30 \%$ thickness reduction (TMT30 sample) has a big value of square of deviations of HV measures when compared with the others samples with distinct thickness reduction. This behavior implies in indications that the deformation has a character very heterogeneous in the interval of thickness reduction.

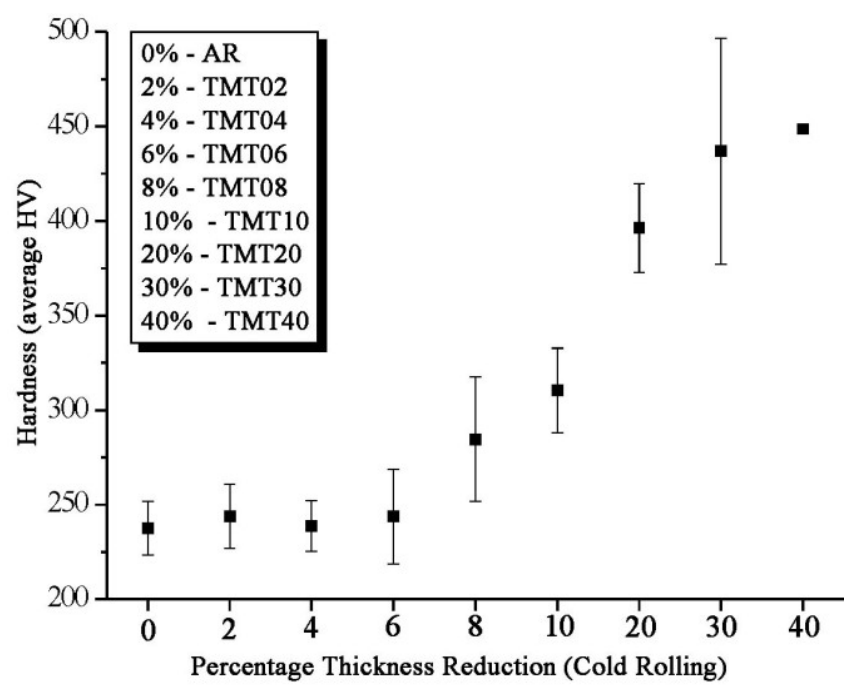

Fig. 2. Vickers Hardness for heat treated sample (HT) and thermomechanical treated samples (TMT02, TMT04, TMT06, TMT08, TMT10, TMT20, TMT30 and TMT 40 samples).

The XRD spectra, shown in Fig. 3, exhibit the gradual evolution of the relative intensities of the peaks, where the (021) B19' diffraction peak increases its intensity with increasing thickness reduction up to $10 \%$. The other B19' XRD peaks ((101), (020), (11 $\overline{1})$ and (002)) decrease their intensities and are overlapping as the percentage of thickness reduction increases.

In agreement with the hardness results (average HV), the B19' XRD spectra presented in the Fig. 3 showed three distinct groups of behavior: (i) the samples with thickness reduction up to $6 \%$ exhibit well defined peaks; (ii) samples with thickness reduction between 8 and $10 \%$ exhibit some overlapping of the (002) and (021) B19' peaks; and (iii) samples with thickness reduction above $20 \%$ exhibit a gradually increasing overlap of the XRD peaks for $38<2 \theta<46^{\circ}$.

Due to this three behavior groups for DSC curves, hardness results and XRD spectra after martensite cold deformation, the $(11 \overline{1})_{\mathrm{B} 19}$, pole figures are discussed in the same groups (Fig. 5a-c, Fig. 5d,e and Fig. 5f-h) compared with free deformation sample (HT), Fig. 4.

According to the previous work [16-18], the HT sample exhibits reinforcement close to central components $\left(\varphi=0^{\circ}, \chi=0^{\circ}\right)$ and close to $\chi=30^{\circ}$, as shown in Fig. 4 by the $(11 \overline{1})_{\mathrm{B} 19}$, and $(110)_{\mathrm{B} 2}$ pole figures. These reinforcements are associated to the following texture components:

(i) for the $\mathrm{B} 19$ ', near the central variants $1:(11 \overline{1})[2 \overline{1} 1]_{\mathrm{B} 19}$, and $4:(11 \overline{1})[\overline{2} 1 \overline{1}]_{\mathrm{B} 19}$, related to $\{110\}<110>_{\mathrm{B} 2}$ and the variants $3:(120)[\overline{2} 11]_{\mathrm{B} 19}$, and $5:(120)[00 \overline{2}]_{\mathrm{B} 19}$, with $\chi=33^{\circ}$ related to $\left.\{111\}<110\right\rangle_{\mathrm{B} 2}$;

(ii) for the B2, near the central component (110) $[110]_{\mathrm{B} 2}$ and the components $\{111\}<110>_{\mathrm{B} 2}$ with $\chi=35^{\circ}$, with $<110>$ along RD. 


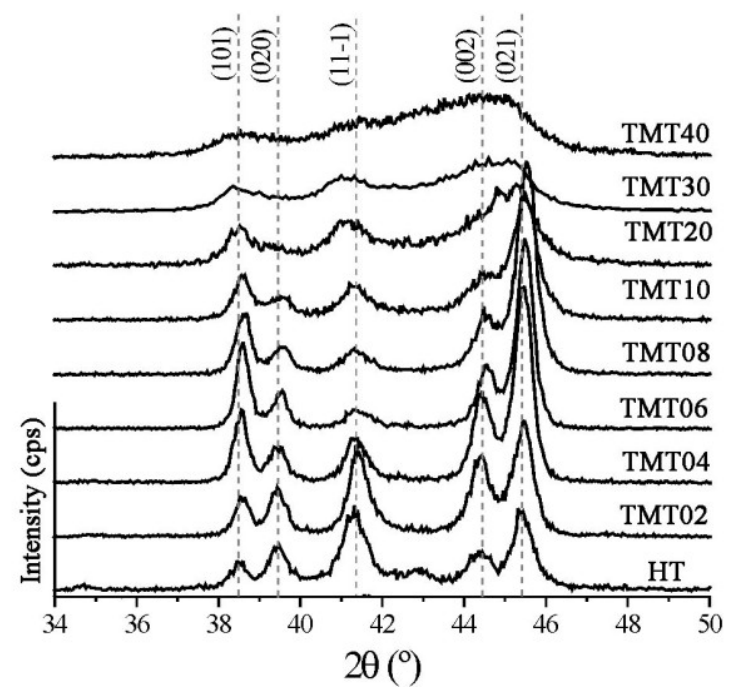

Fig. 3. XRD Spectra for heat treated sample (HT) and thermomechanical treated samples (TMT02, TMT04, TMT06, TMT08, TMT10, TMT20, TMT30 and TMT 40 samples).

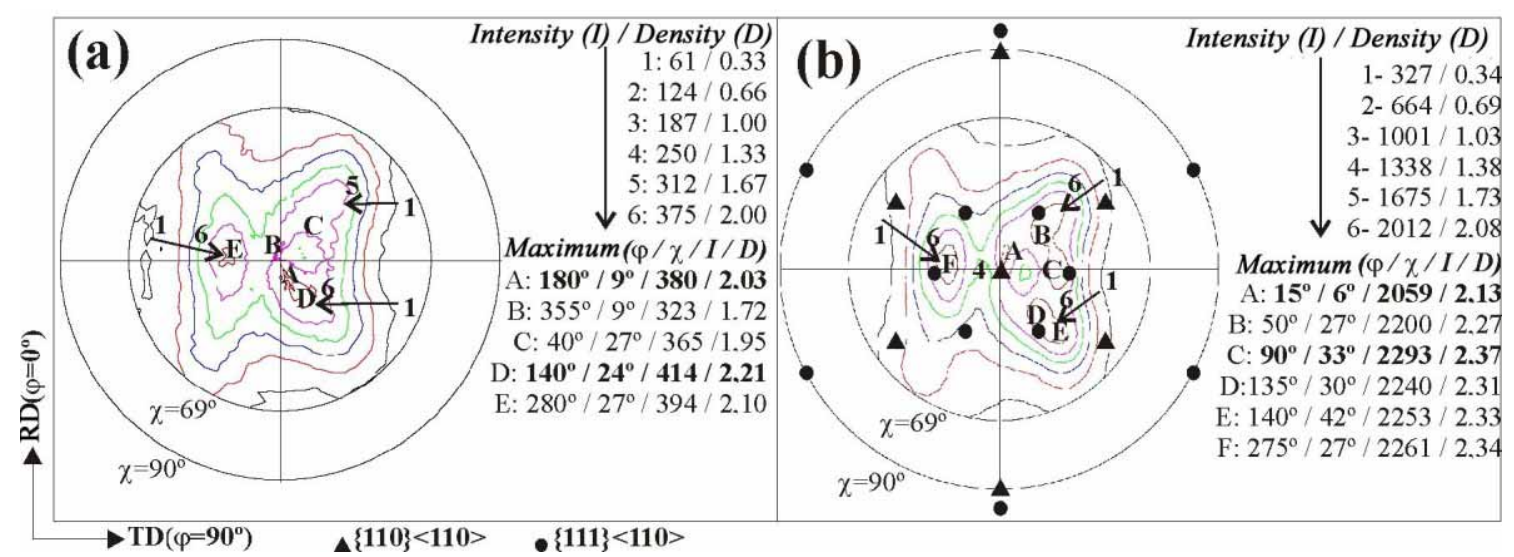

Fig. 4. Pole Figures for HT Sample: (a) $(11 \overline{1})_{\mathrm{B} 19}$, and (b) $(110)_{\mathrm{B} 2}$.

The Fig. 5a-c shows the $(11 \overline{1})_{\mathrm{B} 19}$, pole figures for the sample with thickness reduction up to $6 \%$; as shown by DSC curves, these samples, after heating above $\mathrm{A}_{\mathrm{f}}\left(180^{\circ} \mathrm{C}\right)$, exhibit the complete recovery of the SME. It is possible to notice the changes in the B19' texture components only when the thickness reduction increases to $4 \%$, where the central reinforcement close to $1:(11 \overline{1})[2 \overline{1} 1]_{\mathrm{B} 19}$, and $4:(11 \overline{1})[\overline{2} 1 \overline{1}]_{\mathrm{B} 19}$, variants (related to $\left.\{110\}<110>_{\mathrm{B} 2}\right)$ disappear, while the reinforcement close to $3:(120)[\overline{2} 11]_{\mathrm{B} 19}$, and $5:(120)[00 \overline{2}]_{\mathrm{B} 19}$, (related to $\left.\{111\}<110>_{\mathrm{B} 2}\right)$ is growing.

The Fig. 5 d,e shows the $(11 \overline{1})_{\mathrm{B} 19}$, pole figures for the sample with thickness reduction between 8 and $10 \%$; as shown by DSC curves, these samples, after heating above $\mathrm{A}_{\mathrm{f}}\left(180^{\circ} \mathrm{C}\right)$, exhibit the partial recovery of the SME. This can be verified by Fig. $5 \mathrm{~d}$,e, where the reinforcement close to $\chi=30^{\circ}$, associated to the $\mathrm{B} 19^{\prime}$ texture components close to the $3:(120)[\overline{2} 11]_{\mathrm{B} 19}$, and $5:(120)[00 \overline{2}]_{\mathrm{B} 19}$, variants (related to the $\{110\}<110>_{\mathrm{B} 2}$ ), exhibit a gradual decrease of the intensity in the similar components when the deformation increases from 8 to $10 \%$ (thickness reduction).

The Fig. $5 f-h$ shows the $(11 \overline{1})_{\mathrm{B} 19}$, pole figures for the samples with thickness reduction above $20 \%$ (TMT20, TMT30 and TMT40 samples); as shown by DSC curves, these samples, after heating above $A_{f}$ $\left(180^{\circ} \mathrm{C}\right)$, do not exhibit the SME. This can be verified by Fig. $5 \mathrm{f}-\mathrm{h}$, where the reinforcement close to $\chi=30^{\circ}$, associated to the B19' texture components close to the $3:(120)[\overline{2} 11]_{\mathrm{B} 19}$, and $5:(120)[00 \overline{2}]_{\mathrm{B} 19}$, variants (related to the $\left.\{110\}<110>_{\mathrm{B} 2}\right)$, exhibit a gradual decrease of the intensity in the similar components when the deformation increases from the 20 to $40 \%$ thickness reduction (TMT20, TMT30 and TMT40 samples). Besides, for the TMT40 sample (40\% thickness reduction), reappears the reinforcements close to the central component $\left(\varphi=0^{\circ}\right.$,

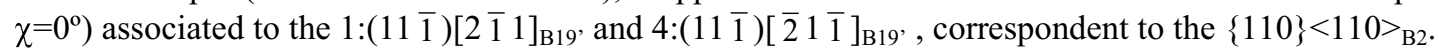




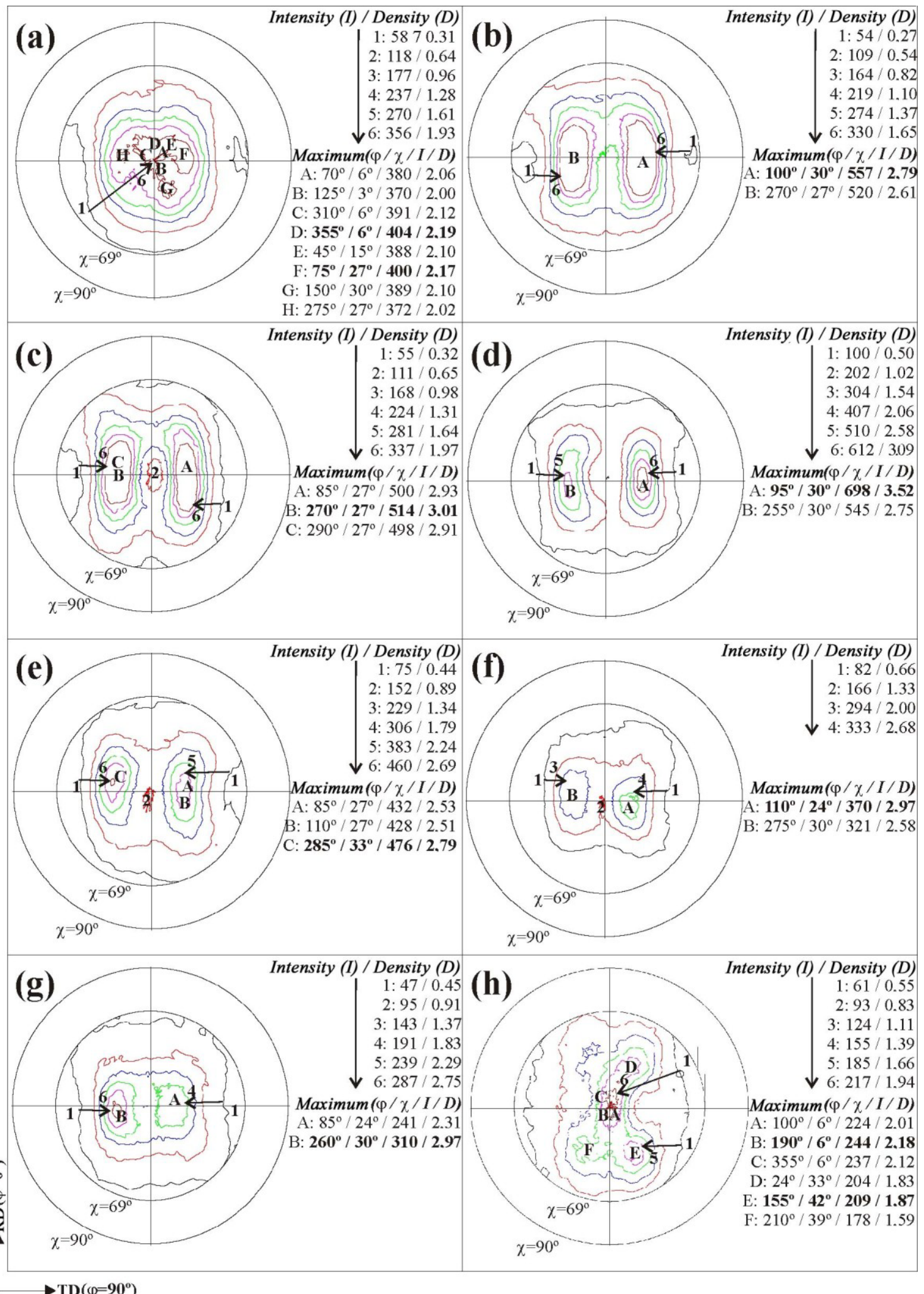

Fig. 5. $(11 \overline{1})_{\text {B19 }}$, Pole Figures for thermomechanical treated samples (TMT02, TMT04, TMT06, TMT08, TMT10, TMT20, TMT30 and TMT 40 samples). 


\section{Conclusions}

The residual stress is a consequence of the deformation above a certain level by cold rolling (above $6 \%$ thickness reduction), due to the considerable increase of the dislocation density. These alterations cause modifications in the reverse transformation temperatures and, consequently, reduce or suppress the SME by heating above $\mathrm{A}_{\mathrm{f}}$.

The crystallographic texture in the Ni-Ti plate formed by the B19' texture components are the result of a deformation resultant imposed to the Ni-Ti alloy in martensitic field (B19'). In the case of cold rolling (marforming), the load is mostly compressive, which maximizes the intensity related to $(021)_{\mathrm{B} 19}$, XRD peak, decreasing the relative intensity of the other XRD peaks in the range of $35<2 \theta<50^{\circ}$. This way, the final texture depends on the initial orientation and the applied load characteristics, as clearly shown by evolution of B19' deformed XRD peaks and the $\mathrm{B} 19$ ' texture components close to $3:(120)[\overline{2} 11]_{\mathrm{B} 19}$, and $5:(120)[00 \overline{2}]_{\mathrm{B} 19}$, variants (related to the $\{111\}<110>_{\mathrm{B} 2}$ ); this effect is more significant for low level of thickness reduction (low level of internal stresses) up to a maximum of $8 \%$. For higher level of deformation, other B19' texture components close to $1:(11 \overline{1})[2 \overline{1} 1]_{\mathrm{B} 19}$, and $4:(11 \overline{1})[\overline{2} 1 \overline{1}]_{\mathrm{B} 19}$, variants (correspondent to $\{110\}<110>_{\mathrm{B} 2}$ ) and close to $2:(10 \overline{2})[211]_{\mathrm{B} 19}, 4:(10 \overline{2})[\overline{2} 1 \overline{1}]_{\mathrm{B} 19}$, and $6:(10 \overline{2})[0 \overline{2} 0]_{\mathrm{B} 19}$, (variants correspondent to a $\left.\{111\}<110>_{\mathrm{B} 2}\right)$ are developed in parallel.

The authors acknowledge FCT/MCTES for the pluriannual financial support of CENIMAT/I3N.

\section{References}

[1] A.L. McKelvey, R.O. Ritchie, Metal. Mat. Trans. 32A, 731(2001).

[2] K.N. Melton, O. Mercier, Acta Metal. 29, 393 (1981).

[3] K.N. Melton, Engineering Aspects of Shape Memory Alloys (Ed. T.W. Duerig, Butterworth-Heinemann, London, 1990), p. 21.

[4] H. F. Lopez, A. Salinas, H. Calderón, Metal. Mat. Trans. A32, 717 (2001).

[5] Y. Liu, Z.L. Xie, J. Van Humbeeck, L. Delaey, Acta Mater. 47, 645 (1999).

[6] S. Miyazaki, K.Otsuka, C.M.Wayman, Acta Metall. 37, 1873 (1989).

[7] L. Zhao, Texture Development and Anisotropic Behaviour in a Ti-45Ni-5Cu (at.\%) Shape Memory Alloy, Ph.D. thesis, University of Twente, Enschede, The Netherlands (1997).

[8] K. Kitamura, S. Miyazaki, H. Iwai e M. Kohl, SMST-97: Proceedings of the Second International Conference on Shape Memory and Superelastic Technologies, Pacific Grove, CA - USA, March 2-6, 1997, edited by (ASM International, 1997), p. 47.

[9] A.S. Paula, J.P.H.G. Canejo, N. Schell, F.M. Braz Fernandes, NIM-B 238, 111 (2005).

[10] F.M. Braz Fernandes, A.S. Paula, J. Canejo, K.K. Mahesh, R.J.C. Silva, R.M.S. Martins, A.M.A. Cardoso, N. Schell, Texture Evolution During Annealing of Ni-Ti Shape Memory Alloy, SMST 2004: Proceedings of the International Conference on Shape Memory and Superelastic Technology, Baden-Baden, Germany, October 3-7, 2004, edited by Matthias Mertmann (ASM International, 2004), p. 45.

[11] T. Bhattacharya, R.V. Kohn, Acta Mater. 44, 529 (1996).

[12] Y.C. Shu, K. Bhattacharya, Acta Mater. 46, 5457 (1998).

[13] A.S. Paula, J.H.P.G. Canejo, K.K. Mahesh, R.J.C. Silva, F.M. Braz Fernandes, R.M.S. Martins, A.M.A. Cardoso, N. Schell, NIM-B 246, 206 (2006).

[14] A.S. Paula, K.K. Mahesh, F.M. Braz Fernandes, R.M.S. Martins, A.M.A. Cardoso, N. Schell, Mat. Sci. Forum 495-497, 125(2005).

[15] A.S. Paula, C.M.L. dos Santos, J.P.H.G. Canejo, K.K. Mahesh, F.M. Braz Fernandes, C.S. da Costa Viana, Textural Evolution in Ti-rich and Ni-rich Ni-Ti Shape Memory Alloys Submitted to Thermomechanical Treatment with Marforming Steps, ABM2007: 62th Annual ABM Congress - Vitória-ES / Brazil (ABM, 2007), p. 3426.

[16] A.S. Paula, J.P.H.G. Canejo, R.M.S. Martins, F.M. Braz Fernandes, Mat. Sci. and Eng. A378, 92 (2004).

[17] F.M. Braz Fernandes, A.S. Paula, J. Canejo, K.K. Mahesh, R.J.C. Silva, SMST 2004: Proceedings of the International Conference on Shape Memory and Superelastic Technology, Baden-Baden, Germany, October 3-7, 2004, edited by Matthias Mertmann (ASM International, 2004), p. 51.

[18] A.S. Paula, Tratamentos termomecânicos de ligas do sistema Ni-Ti. Caracterização estrutural e optimização das propriedades associadas ao efeito de memória de forma, PhD Thesis, FCT/UNL, Lisbon - Portugal (2006).

[19] E. Hornbogen, Mater. Sci. Forum 455-456, 335 (2004). 